\title{
Mammography Screening within the Context of the Theory of Planned Behavior: The Role of Personality Traits and Personal Factors
}

\author{
Fay Griva ${ }^{1}$, Fotios Anagnostopoulos ${ }^{1}$, Kleanthi Gourounti ${ }^{1}$, Philippa Kolokotroni ${ }^{1} \&$ Natalia Koutrouli ${ }^{1}$ \\ ${ }^{1}$ Department of Psychology, Panteion University of Social and Political Sciences, Athens, Greece \\ Correspondence: Fotios Anagnostopoulos, Department of Psychology, Panteion University of Social and \\ Political Science, 136 Syggrou Ave. 176 71, Athens, Greece. E-mail: fganagn@hol.gr
}

Received: May 15, 2013

Accepted: July 8, $2013 \quad$ Online Published: August 15, 2013

doi:10.5539/ijps.v5n3p98

URL: http://dx.doi.org/10.5539/ijps.v5n3p98

\begin{abstract}
The present study examined the associations between optimism, personal characteristics and theory of planned behavior (TPB) components for mammography screening. Most of the results were in line with TPB which proposed that intention would be the most proximal determinant of a behavior and the effects of other factors including attitudes and perceived behavioral control on behavior would be mediated through intention. However, a number of demographic and health-related factors, including age and a previous benign breast disease emerged as independent factors associated with mammography screening, providing evidence that personal factors should be taken into account in future applications of the TPB when examining mammography screening behavior.
\end{abstract}

Keywords: mammography screening, theory of planned behavior, optimism

\section{Introduction}

Mammography screening is considered an effective way to detect breast cancer early. Although there is considerable evidence to suggest that mammography screening is associated with reduced rates of mortality (Humphrey, Helfand, Chan \& Woolf, 2002; Madlensky, Goel, Polzer, \& Ashbury, 2003; Schopper \& de Wolf, 2009), there is often a discrepancy reported between recommended and actual use of mammograms (Botha et al., 2003). In an attempt to identify the factors associated with mammography screening, a number of social cognition models such as the health belief model (HBM; Becker, 1974; Rosenstock, Strecher, \& Becker, 1988), or the common-sense model of illness representations (CSM; Leventhal, Nerenz, \& Steele, 1984; Leventhal; Leventhal, \& Contrada, 1998) and the theory of planned behavior (TPB) (Ajzen, 1991) have been applied in various settings and populations. A recent study in Greece used an integrated framework combing the HBM and the CSM applied to screening for breast cancer (Anagnostopoulos et al., 2012). The present study makes use of the TPB framework to examine mammography screening. The TPB identifies intention as the most proximal determinant of behavior, and attitude, subjective norm (influence and pressure from important others) (SN) and perceived behavioral control ( $\mathrm{PBC}$ ), as the socio-cognitive determinants of intention to engage in a behavior. Meta-analyses provide empirical support for the predictive utility of the TPB (Armitage \& Conner, 2001; Cooke \& French, 2007). According to Armitage and Conner (2001) the TPB accounts for $39 \%$ of the variance in intention and $27 \%$ of the variance in predicting behavior. Although substantial variance is explained, a large proportion of it is left unexplained and may be attributed to other factors external to the model. In an attempt to increase its predictive utility, recent research has focused on expanding the TPB with the inclusion of other factors, such as moral norms (e.g., McMillan, Higgins, \& Conner, 2005), self-identity (e.g., Moan \& Rise, 2006), anticipated regret (e.g., Richard, van der Pligt, \& de Vries, 1996), desire (e.g., Taylor, Bagozzi, \& Gaither, 2005), and personality traits (e.g., Rhodes, Courneya, \& Jones, 2002). Ajzen (1991) has proposed that external variables such as personal variables, personality traits, or other individual differences variables, may influence behavior indirectly by affecting the main components of the TPB. However, research has provided some evidence for the existence of a direct relation between external variables of this kind and health behaviors. A systematic review of prospective studies on physical exercise revealed that the relation between personality, including conscientiousness and extraversion traits, and exercise behavior was unmediated by the TPB components (McEachan, 2004). In addition, a recent study on eating behavior (Churchill, Jessop, \& Sparks, 2008) found that impulsivity predicted consumption of high-calorie snacks over and above the TPB components. 
Although the TPB is one of the most commonly used models in health behavior, the number of studies that examine mammography screening within this framework is remarkably small (Griva, Anagnostopoulos, \& Madoglou, 2009). Research attempts to expand the TPB include external variables such as affect (Montano, Thompson, Taylor, \& Mahloch, 1997), self-efficacy beliefs (Tolma, Reininger, Ureda, \& Evans, 2006), and cultural factors, namely fatalism (Terán et al., 2007) and religiosity (Bowie et al., 2003). However, these factors may either be considered redundant (i.e., items that measure affect semantically resemble items that measure attitudes, and items that measure perceived control semantically resemble items that measure self-efficacy beliefs respectively), or non applicable to our study because in western populations mammography screening does not seem to be that much affected by cultural factors as in other populations (Austin et al., 2002; Soskolne, Marie, \& Manor, 2007). In addition to these factors, some studies have explored the effect of sociodemographic characteristics and health-related variables, such as family history of breast cancer, or a previous benign diagnosis, on both intention and mammography screening after controlling for TPB variables. Findings reveal direct associations between screening and some of these variables including age, education, and practice of breast-self examination or clinical breast examination (Bowie et al., 2003; Drossaert, Boer, \& Seydel, 2003; Tolma et al., 2006).

In the light of these findings, the purpose of the present study was to explore the association between external variables and TPB constructs for mammography screening. Apart from the inclusion of sociodemographic and health-related information, optimism, measured as a personality trait, was selected to be included in the expanded model. Our rational for including optimism was based on previous research reporting associations between optimism and health-related behaviors (Robbins, Spence, \& Clark, 1991; Steptoe, 1994), including mammography screening (Farmer, Reddick, D'Agostino, \& Jackson, 2007). Furthermore, the majority of the studies that have incorporated personality traits within the TPB framework focus predominantly on general traits like the Big-Five factors (Conner \& Abraham, 2001; Courneya, Bobick, \& Schinke, 1999; Rhodes, Courneya, \& Jones, 2002). Research suggests that specific personality traits such as optimism, are better predictors of specific measures of health behaviors, rather than general personality traits such as neuroticism that seem to predict better general measures of health (Wasylkiw \& Fekken, 2002). To the best of our knowledge, this is the first study that attempts to explore the relation between personality traits, TPB components and mammography screening. Therefore, the aim of the present study was to test the hypothesis that external factors, namely optimism and sociodemographic and health-related factors would be significantly associated with mammography screening after controlling for TPB components.

\section{Method}

\subsection{Participants and Procedure}

A convenience sample of 194 women was recruited from attendees in the outpatient clinics of a General Hospital in Athens, Greece. The inclusion criteria were: a) being 40 years old and above, which is the suggested age for a woman to undertake mammography screenings according to the guidelines of the Senologic Hellenic Society and most European countries (Hakama et al., 2008), b) having a good knowledge of the Greek language.The exclusion criterion was a previous malignant breast cancer diagnosis. Women were approached while they were waiting to be referred to a general practitioner and were informed of the purpose of the study. Those women who were found eligible to participate in the study $(n=242)$, were presented with further information in writing about the purpose of the study, their ensured anonymity and their right to withdraw at any point from the study. Accepting to complete and return the questionnaires was assumed to equate with assent to participate in the study. A substantial number of women returned the questionnaires $(n=215)$. The main reason for those who did not participate was time constrains. The total number of participants was 194, due to removal from the sample those with partially completed questionnaires.

\subsection{Measures}

The TPB questionnaire was constructed in the proposed TPB - format (Ajzen, 2002; Francis et al., 2004). Attitudes toward mammography screening were measured using three items: The first item "Getting a mammogram every two years would be good" was selected to reflect an overall evaluation of the behavior. The second item "Getting a mammogram every two years would be useful" was selected to reflect an instrumental dimension (i.e., whether the behavior would achieve something) while the third item "Getting a mammogram every two years would be safe" was selected to reflect an experiential dimension (i.e., how the person would feel about the behavior). Subjective norms were measured using three items: "Most people who are important to me think I should get a mammogram every two years", "Most people who are important to me expect me to get a mammogram every two years" and "Most people who are important to me would approve of me getting a 
mammogram every two years. Perceived behavioral control was measured with three items: "Whether or not I get a mammogram every two years is entirely up to me", "I believe it is feasible to get a mammogram every two years" and "I am confident that if I wanted I would be able to get a mammogram every two years. Intention to participate in mammography screening was measured using three items: "I plan to get a mammogram every two years", "I want to get a mammogram every two years" and "I will try to get a mammogram every two years". All of the above items were answered on a Likert scale ranging from 1 (strongly disagree) to 5 (strongly agree). Findings from factor analyses using principal axis factoring (PAF) with oblique rotation revealed that all items had loadings $>0.35$ on their respected factors; the factors had internal consistency reliabilities ranging from 0.65 (PBC) to 0.83 (intention), were highly correlated $(\mathrm{p}<.01)$ and explained $56.25 \%$ of the variance..Intention was highly correlated with attitudes $(\mathrm{r}=.609)$, SN $(\mathrm{r}=.462)$, and PBC $(\mathrm{r}=.590)$. Significant correlations were observed between attitudes and SN $(\mathrm{r}=.561)$, attitudes and PBC $(\mathrm{r}=.658)$ and between PBC and SN $(\mathrm{r}=.482)$.

Optimism was measured using the Life Orientation Test-Revised (LOT-R; Scheier et al., 1994). It is a 10-item scale self-report scale (with 4 filler items) assessing dispositional optimism (i.e., generalized expectancies for favourable versus unfavourable outcomes) on a 5-point Likert scale ranging from 1 (strongly disagree) to 5 (strongly agree). The Greek version of the LOT-R has been found to have satisfactory internal consistency reliability (Cronbach's $\alpha=.71$ ) (Lyrakos et al., 2010). Behavior was measured using self-reported number of life-time mammograms obtained, ranging from 1 (none) to 5 (more than 10). Basic demographic and health-related information included: age, marital status, economic status and educational level, regular clinical breast examination and breast self-examination practice, family history of breast cancer, and presence of benign breast disease in the past. Similar variables have been measured in previous studies on mammography screening in medical settings (e.g., Tolma et al., 2006).

\subsection{Statistical Analysis}

For the initial examination of the data, SPSS version 17.0 was used. After removing 8 cases due to more than $50 \%$ of incomplete information in the battery of questionnaires administered, an analysis of the missing values in the remaining questionnaires was performed using Missing Value Analysis (MVA) to determine whether these values were missing at random. Expectation Maximization method was then used to replace these values. Demographic and health-related characteristics of the sample were presented using descriptive statistics, such as means and frequencies and correlational analysis was used to examine the relationships between continuous variables and mammography screening. Path analyses were then performed using AMOS 20.0 to examine whether the model adequately fitted to the data. Direct and indirect associations among variables were estimated, and mediation was examined. The goodness of fit of the model was assessed using a number of indices. A satisfactory fit was considered when the chi-square test, calculated using the Satorra- Bentler robust estimation procedure, was found to be non-significant. Apart from the $\chi^{2}$, the fit of the model was also evaluated with the root-mean-square error of approximation (RMSEA; a value close to .06 or less indicated a good fit), the Bentler-Bonett normed fit index (NFI; a value close to or greater than .90 indicated a good fit), the goodness of fit index (GFI) and the comparative fit index (CFI), where values close to .95 or greater indicated an adequate fit of the model (Hu and Bentler 1999). The Akaike Information Criterion (AIC) was used as an indicator of parsimony in model fit, where a lower value of AIC indicated a more parsimonious model (Raykov \& Marcoulides, 2000).

\section{Results}

The mean age of the participants was 50.9 years ( $\mathrm{SD}=7.7$ ), ranging from 40 to 75 years. Most of the respondents were married $(76.3 \%)$, had a full time occupation $(59.8 \%)$, and the majority had either completed high school $(57.2 \%)$ or had attended university $(36.6 \%)$. Most of the respondents were not practicing breast self-examination $(52.1 \%)$, though the majority had received annual clinical breast examination $(53.1 \%)$. In addition, the majority of women $(82 \%)$ had never been diagnosed with a benign breast disease in the past (Table $1)$. 
Table 1. Demographic and health-related characteristics of the sample

\begin{tabular}{|c|c|c|}
\hline Variable & Frequency & $\%$ \\
\hline \multicolumn{3}{|l|}{ Age, years } \\
\hline $40-49$ & 108 & 55.7 \\
\hline $50-59$ & 60 & 30.9 \\
\hline 60 and above & 26 & 13.4 \\
\hline \multicolumn{3}{|l|}{ Education (years) } \\
\hline Low $(0-6)$ & 12 & 6.2 \\
\hline Medium (7-12) & 111 & 57.2 \\
\hline $\operatorname{High}(13-16)$ & 71 & 36.6 \\
\hline \multicolumn{3}{|l|}{ Marital status } \\
\hline Married & 148 & 76.3 \\
\hline Single & 16 & 8.2 \\
\hline Divorced/Widowed & 30 & 15.5 \\
\hline \multicolumn{3}{|l|}{ Employment status } \\
\hline Employed & 116 & 59.8 \\
\hline Unemployed & 78 & 40.2 \\
\hline \multicolumn{3}{|l|}{ Economic status } \\
\hline Very Good & 14 & 7.2 \\
\hline Good & 94 & 48.5 \\
\hline Medium & 73 & 37.6 \\
\hline Poor & 13 & 6.7 \\
\hline \multicolumn{3}{|l|}{ BSE status } \\
\hline $\mathrm{Yes}^{\mathrm{a}}$ & 93 & 47.9 \\
\hline No & 101 & 52.1 \\
\hline \multicolumn{3}{|l|}{ CBE status } \\
\hline Never & 40 & 20.6 \\
\hline More than 2 years & 31 & 16.0 \\
\hline Every 2 years & 20 & 10.3 \\
\hline Once a year & 103 & 53.1 \\
\hline \multicolumn{3}{|l|}{ Family history } \\
\hline Yes & 48 & 24.7 \\
\hline No & 146 & 75.3 \\
\hline \multicolumn{3}{|l|}{ Benign breast disease } \\
\hline Yes & 35 & 18.0 \\
\hline No & 159 & 82.0 \\
\hline
\end{tabular}

Note. BSE = breast self-examination; $\mathrm{CBE}=$ clinical breast examination.

a. Response indicates that a woman performs BSE at least once every 1 to 2 months

Correlational analyses revealed significant relationships between TPB components and mammography screening. Intention was associated with screening behavior $(\mathrm{r}=.498, \mathrm{p}<.01)$. Significant correlations were observed among all TPB components. However no significant correlations were observed between optimism and the rest of the variables (Table 2). 
Table 2. Correlations among main psychological variables

\begin{tabular}{|c|c|c|c|c|c|}
\hline & 1 & 2 & 3 & 4 & 5 \\
\hline \multicolumn{6}{|l|}{$\begin{array}{l}\text { 1. Mammography } \\
\text { screening behavior }\end{array}$} \\
\hline 2. Intention & $.498 * *$ & & & & \\
\hline 3. Attitudes & $.285 * *$ & $.609 * *$ & & & \\
\hline 4. Subjective norms & $.296 * *$ & $.520 * *$ & $.588 * *$ & & \\
\hline $\begin{array}{l}\text { 5. Perceived } \\
\text { behavioral control }\end{array}$ & $.269 * *$ & $.590 * *$ & $.658 * *$ & $.549 * *$ & \\
\hline 6. Optimism & -.009 & -.010 & .128 & .130 & .006 \\
\hline
\end{tabular}

Note. $* * \mathrm{p}<.01$

A proposed model was then tested which included all variables, along with demographic and health-related characteristics (Figure 1). The hypothesised direct association between intention and behavior was significant $(\beta=.451, \mathrm{p}<.001)$. The direct association between attitudes and intention was significant $(\beta=.339, \mathrm{p}<.001)$ as was the relation between perceived behavioral control and intention $(\beta=.296, p<.01)$, but the association between subjective norms and intention was not significant $(\beta=.178, p>.05)$. In addition, as presented in Table 3, direct associations were observed between age and mammography screening $(\beta=.427, p<.001)$ and previous benign breast disease and mammography screening $(\beta=.256, \mathrm{p}<.001)$.

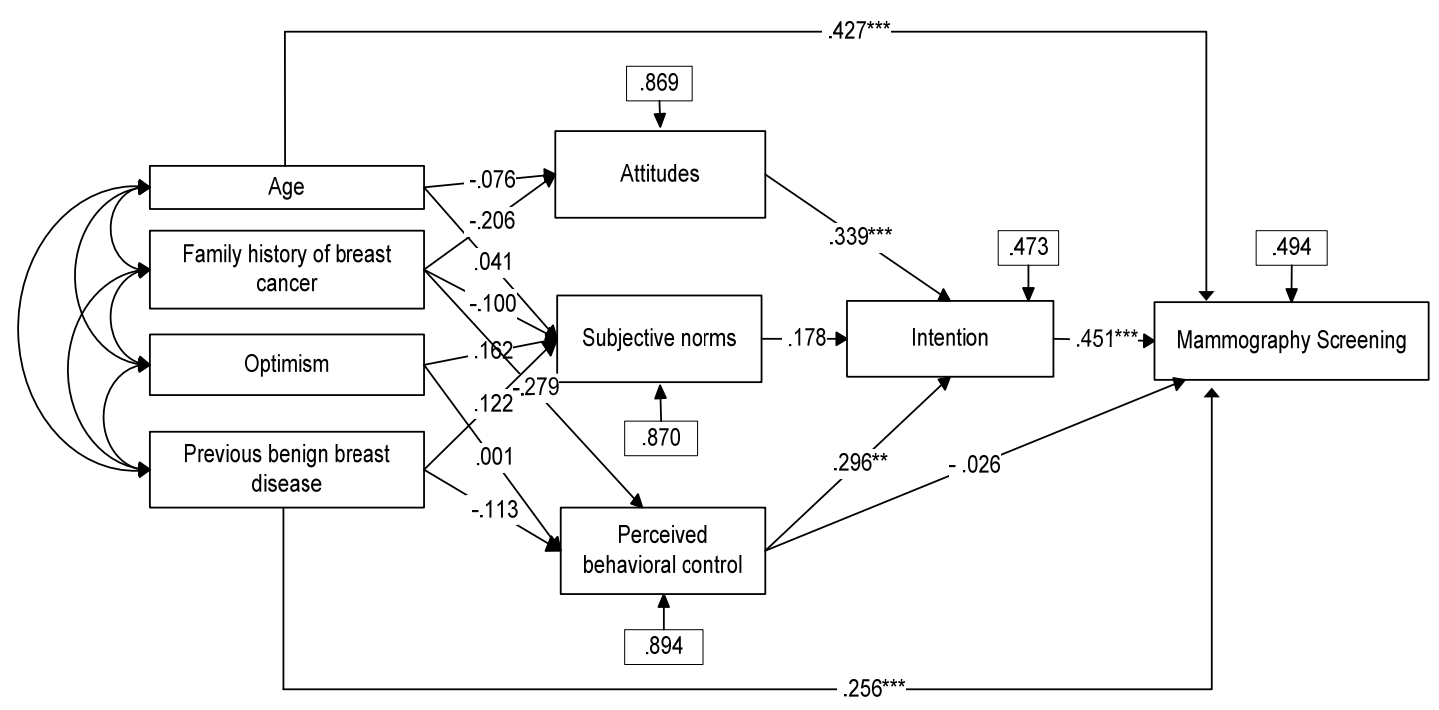

Figure 1. Model including TPB dimensions, optimism, demographic and health-related variables, and mammography screening

Note. $* * \mathrm{p}<.01, * * * \mathrm{p}<.001$. Standardized path coefficients are presented in the middle of straight lines. Numbers enclosed in rectangles represent disturbances of the corresponding measured variables, that is variances unexplained by the other explanatory variables included in the model.

Significant indirect associations were observed between attitudes and behavior through intention $(\beta=.153, \mathrm{p}<.01)$ and between perceived behavioral control and behavior through intention $(\beta=.133, \mathrm{p}<.05)$. The proposed variables included in this model accounted for $52.7 \%$ of the variance in intention and $50.6 \%$ of the variance in mammography screening. The proposed model exhibited good fit to the data, Satorra- Bentler $\chi^{2}(15)=10.14, p$ $=.81$, confirmed by the other fit indices $(\mathrm{RMSEA}=.022 ; \mathrm{NFI}=.99 ; \mathrm{CFI}=.99 ; \mathrm{GFI}=.98 ; \mathrm{AIC}=90.14)$. 
Table 3. Direct effects of demographic and health-related variables, as well as optimism, on TPB components

\begin{tabular}{|c|c|c|c|}
\hline Paths & B (SE) & $\mathrm{t}$ & $\beta$ \\
\hline Attitudes $\rightarrow$ Intention & $.350(.105)$ & $3.341 * * *$ & .339 \\
\hline Subjective norms $\rightarrow$ Intention & $.346(.238)$ & 1.451 & .178 \\
\hline Perceived behavioral control $\rightarrow$ Intention & $.156(.050)$ & $3.145^{* *}$ & .296 \\
\hline Perceived behavioral control $\rightarrow$ Behavior & $-.010(.035)$ & -0.272 & -.026 \\
\hline Intention $\rightarrow$ Behavior & $.315(.060)$ & $5.225 * * *$ & .451 \\
\hline Age $\rightarrow$ Behavior & $.073(.013)$ & $5.455 * * *$ & .427 \\
\hline Age $\rightarrow$ Attitudes & $-.018(.040)$ & -.454 & -.076 \\
\hline Age $\rightarrow$ Perceived behavioral control & $-.011(.068)$ & -.155 & -.023 \\
\hline $\begin{array}{l}\text { Previous benign breast disease } \rightarrow \\
\text { Behavior }\end{array}$ & $.365(.109)$ & $3.345 * * *$ & .256 \\
\hline $\begin{array}{l}\text { Previous benign } \text { breast disease } \rightarrow \\
\text { Attitudes }\end{array}$ & $.025(.397)$ & 0.063 & .013 \\
\hline $\begin{array}{l}\text { Family history of breast cancer } \rightarrow \\
\text { Attitudes }\end{array}$ & $-.408(.344)$ & -1.188 & -.206 \\
\hline $\begin{array}{l}\text { Family history of breast cancer } \rightarrow \\
\text { Subjective norms }\end{array}$ & $-.105(.205)$ & -0.514 & -.100 \\
\hline $\begin{array}{l}\text { Family history of breast cancer } \rightarrow \\
\text { Perceived behavioral control }\end{array}$ & $-1.074(.578)$ & -1.857 & -.279 \\
\hline Optimism $\rightarrow$ Attitudes & $.077(.074)$ & 1.042 & .164 \\
\hline $\begin{array}{l}\text { Optimism } \rightarrow \text { Perceived behavioral } \\
\text { control }\end{array}$ & $.001(.129)$ & 0.009 & .001 \\
\hline Optimism $\rightarrow$ Subjective norms & $.040(.044)$ & 0.905 & .162 \\
\hline
\end{tabular}

\section{Discussion}

The purpose of the current study was to examine the associations between external variables, TPB constructs and mammography screening behavior. Most of the findings were consistent with that expected from the theoretical framework of TPB. The direct association found between intention and mammography screening confirmed that intention was the most significant proximal determinant of behavior, as suggested by the TPB. Although intention does not necessarily mean that action will follow, referred in literature as the "intention-behavior gap", prospective studies on breast cancer screening indicate successful prediction of mammography utilization within up to six years (Drossaert, Boer, \& Seydel, 2003; Rutter, 2000). Furthermore, the association between attitudes and intention and between perceived behavioral control and intention was in line with the tenets of the TPB. In the present study intention mediated the relationship between attitudes and mammography screening, and between perceived behavioral control and mammography screening. However, the subjective norm component was not significantly associated with intention. Previous research findings concerning the effect of subjective norm on intentions and behavior seem to be contradictory. For some of studies, subjective norm appears as the most significant predictor of mammography intention (e.g., Tolma et al., 2006). However, there are studies that report either a weak association (e.g., Rutter, 2000) or no association at all (e.g., O'Neil et al., 2008). It has been suggested that the relative weight of each TPB predictor may vary according to the behavior and the population in question (Ajzen \& Fishbein, 2004). A meta-analytic study on the utility of TPB in predicting screening intentions and attendance concluded that subjective norms were the weakest predictors of intention compared to attitudes and perceived control and that the size of this relationship was particularly small for mammography screening compared to other screening behaviors (Cooke \& French, 2007). According to researchers, most women may take it for granted that their important others will want them to get a mammogram, and this may lead to reduced variability in their perceptions of normative pressure regarding this specific behavior.

Although the indirect association between attitudes and perceived behavioral control, and mammography 
screening behavior was in line with TPB propositions, the direct associations found between age and a diagnosis of benign lesions in the past with screening behavior, provided evidence that the influence of specific factors on mammography screening was not mediated by TPB components. Similar findings have been reported in previous studies that examined the effect of external characteristics on mammography screening. In the study by Tolma et al. (2006), age and educational level and health-related factors such as practicing clinical breast examination and breast self-examination, significantly contributed to the prediction of intention after controlling for the TPB components. Similar effects were reported in the study by Drossaert, Boer, and Seydel (2003) for age, educational level and marital status on predicting mammography screening attendance. Findings of the present study suggested that for older women and for women who had been diagnosed with benign lesions in the past, attitudes, normative pressure, or perceptions of behavioral control might not play a pivotal role in their decision about undertaking mammography screening. Their age or the previous benign disease might result in equating mammography screening with a health necessity rather than a choice to decide upon acting or not.

In relation to optimism, which was added to examine the association of a personality characteristic with the TPB components, results indicated lack of any effect, either direct or indirect on the TPB components and mammography screening behavior. Although in previous research optimism has been associated with the practice of health behaviors such as alcohol consumption, smoking, healthy eating and physical exercise in healthy populations (Robbins, Spence, \& Clark, 1991; Steptoe, 1994) most of the studies examine the effect of dispositional optimism through its association with factors such as coping strategies or emotional affect (Baker, 2006; Chang \& Sanna, 2003; Taylor et al., 1992). This also applies to studies that examine mammography screening, where the effect of optimism is associated with either perceptions of risk and worry (Facione, 2002; MacGregor et al., 2004) or perceptions of benefits and barriers within the theoretical framework of the Health Belief Model (Farmer et al., 2007) and no direct associations between optimism and mammography screening behavior have been reported either. In addition, in previous research, optimism has been associated with perceiving less barriers in adopting mammography screening (Farmer et al., 2007). Therefore, in the present study, one could expect that optimism might have been associated with perceptions of control. However, it has been suggested that these two constructs are not entirely similar in the sense that perceived behavioral control as a construct within the theoretical framework of TPB incorporates both the perception of external barriers and a person's perceived efficacy of overcoming these barriers (Ajzen, 2002a; Trafimow et al., 2002).

A number of limitations are present in this study. These include the small sample size which may have resulted in failure to detect meaningful differences as statistically significant, and the cross sectional design of the study that does not allow the inference of causal relationships among variables. In addition, collection of the data was based on self-reported measures and this might have resulted in participants providing socially desirable answers or other response biases such as the recall bias about their practicing of mammography screening. Finally, the present study did not examine other variables related to mammography screening such as knowledge about breast cancer and breast cancer screening benefits, or emotional responses to screening.

The present study represents an attempt to explore the role of additional factors associated with of mammography screening within the TPB context. The inclusion of optimism does not seem to add to the predictive utility of the TPB for mammography screening. Nevertheless, because recent attempts to expand TPB provide evidence that personality traits may enhance the predictive utility of TPB (Conner \& Abraham, 2001; Churchill et al., 2008; Courneya, Bobick, \& Schinke, 1999) it may be worthy of future investigation to examine whether there are effects of this kind present for mammography screening. In addition, and since little consideration has been given in the literature to the effect of the external personal factors within the TPB context, it is worthwhile to examine further the effect of heath-related factors and demographic characteristics in future applications of the TPB model.

\section{References}

Anagnostopoulos, F., Dimitrakaki, C., Fitzsimmons, D., Potamianos, G., Niakas, D., \& Tountas, Y. (2012). Health beliefs and illness perceptions as related to mammography uptake in radomnly selected women in Greece. Journal of Clinical Psychology in Medical Settings, 19, 147-164. http://dx.doi.org/10.1007/s10880-011-9272-1

Ajzen, I. (1991). The theory of planned behaviour. Organizational Behaviour and Human Decision Processes, 50, 179-211. http://dx.doi.org/10.1016/0749-5978(91)90020-T

Ajzen, I. (2002). Constructing a TPB questionnaire: Conceptual and methodological considerations. Retrieved from http://www.people.umass.edu/aizen/pdf/tpb. measurement.pdf

Ajzen, I. (2002a). Perceived behavioural control, self-efficacy, locus of control, and the theory of planned 
behaviour. Journal of Applied Social Psychology, $\quad 32, \quad 1-20$. http://dx.doi.org/10.1111/j.1559-1816.2002.tb00236.x

Ajzen, I., \& Fishbein, M. (2004). Questions raised by a reasoned action approach: Comment on Ogden (2003). Health Psychology, 23, 431-434. http://dx.doi.org/10.1037/0278-6133.23.4.431

Armitage, C., \& Conner, M. (2001). Efficacy of the theory of planned behavior: A meta-analytic review. British Journal of Social Psychology, 40, 471-497. http://dx.doi.org/10.1348/014466601164939

Austin, L. T., Ahmad, F., McNally, M. J., \& Stewart, D. E. (2002). Breast and cervical cancer screening in Hispanic women: A literature review using the health belief model. Women Health Issues, 12, 122-128. http://dx.doi.org/10.1016/S1049-3867(02)00132-9

Becker, M. H., (1974). The health belief model and sick role behavior. Health Education Monographs, 2, 409-419.

Baker, S. R. (2006). Toward an idiothetic understanding of the role of social problem solving in daily event, mood and health experiences: A prospective daily diary approach. British Journal of Health Psychology, 11, 513-531. http://dx.doi.org/10.1348/135910705X57647

Bowie, J. V., Curbow, B., LaVeist, T. A., Fitzgerald, S., \& Zabora, J. (2003). The theory of planned behavior and intention to repeat mammography among African-American women. Journal of Psychosocial Oncology, 21, 23-42. http://dx.doi.org/10.1300/J077v21n04_02

Botha, J. L., Bray, F., Sankila, R., \& Parkin, D. M. (2003). Breast cancer incidence and mortality trends in 16 European countries. European Journal of Cancer, 39, 1718-1729. http://dx.doi.org/10.1016/S0959-8049(03)00118-7

Chang, E. C., \& Sanna, L. J. (2003). Optimism, accumulated life stress, and psychological and physical adjustment: Is it always adaptive to expect the best? Journal of Social and Clinical Psychology, 22, 96-114. http://dx.doi.org/10.1521/jscp.22.1.97.22767

Churchill, S., Jessop, D., \& Sparks, P. (2008). Impulsive and/or planned behaviour: Can impulsivity contribute to the predictive utility of the theory of planned behaviour? British Journal of Social Psychology, 47, 631-646. http://dx.doi.org/10.1348/014466608X284434

Conner, M., \& Abraham, C. (2001). Conscientiousness and the theory of planned behavior: Toward a more complete model of the antecedents of intentions and behavior. Personality and Social Psychology Bulletin, 27, 1547-1561. http://dx.doi.org/10.1177/01461672012711014

Courneya, K. S., Bobick, T. M., \& Schinke, R. J. (1999). Does the theory of planned behavior mediate the relationship between personality and exercise behavior? Basic and Applied Social Psychology, 21, 317-324.

Cooke, R., \& French, D. P. (2007). How well do the theory of reasoned action and theory of planned behavior predict intentions and attendance at screening programmes? A meta-analysis. Psychology and Health, 23, 745-765. http://dx.doi.org/10.1080/08870440701544437

Drossaert, C. H. C., Boer, H., \& Seydel, E. R. (2003). Prospective study on the determinants of repeat attendance and attendance patterns in breast cancer screening using the theory of planned behavior. Psychology \& Health, 18, 551-565. http://dx.doi.org/10.1080/0887044031000141207

Facione, N. C. (2002). Perceived risk of breast cancer. Influence of heuristic thinking. Cancer Practice, 10, 256-262. http://dx.doi.org/10.1046/j.1523-5394.2002.105005.x

Farmer, D., Reddick, R., D’Agostino, R., \& Jackson, S. (2007). Psychosocial correlates of mammography screening in older African American women. Oncology Nursing Forum, 34, 117-123. http://dx.doi.org/10.1188/07.ONF.117-123

Francis, J. J., Eccles, M. P., Johnston, M., Walker, A., Grimshaw, J., Foy, R., Kaner, E. F. S., Smith, L., \& Bonetti, D. (2004). Constructing questionnaires based on the theory of planned behaviour: A manual for the health services researchers. Newcastle: Centre for Health Services Research. Retrieved from http://www.rebeqi.org/ViewFile.aspx?itemID=212

Griva, F., Anagnostopoulos, F., \& Madoglou, S. (2009). Mammography screening and the theory of planned behavior: Suggestions towards an extended model of prediction. Women \& Health, 49(8), 662-681. http://dx.doi.org/10.1080/03630240903496010

Hakama, M., Coleman, M. P., Alexe, D. M., \& Anssi, A. (2008). Cancer screening: Evidence and practice in 
Europe 2008. European Journal of Cancer, 44, 1404-1413. http://dx.doi.org/10.1016/j.ejca.2008.02.013

Humphrey, L. L., Helfand, M., Chan, B. K. S., \& Woolf, S. H. (2002). Breast cancer screening: Summary of the evidence. Annals of Internal Medicine, 137, 344-346. http://dx.doi.org/10.7326/0003-4819-137-5_Part_1-200209030-00012

Leventhal, H., Leventhal, E. A., \& Contrada, R. J. (1998). Selfregulation, health, and behavior: A perceptual-cognitive approach. Psychology and Health, 13, 717-733. http://dx.doi.org/10.1080/08870449808407425

Leventhal, H., Nerenz, D. R., \& Steele, D. J. (1984). Illness representations and coping with health threats. In A. Baum, S. E. Taylor, \& J. E. Singer (Eds.), Handbook of psychology and health: Social psychological aspects of health (Vol. 4, pp. 219-252). Hillsdale: Erlbaum.

Lyrakos, G. N., Damigos, D., Mavreas, V., Kostopanagiotou, G., \& Dimoliatis, I. D. K. (2009). A translation and validation study of the Life Orientation Test Revised in the Greek speaking population of nurses among three hospitals in Athens and Ioannina. Social Indicators Research, 95, 129-142. http://dx.doi.org/10.1007/s11205-009-9453-6

Madlensky, L., Goel, V., Polzer, J., \& Ashbury, F. D. (2003). Assessing the evidence for organized cancer screening programs. European Journal of Cancer, 39, 1648-1653. http://dx.doi.org/10.1016/S0959-8049(03)00315-0

McEachan, R. R. C. (2004). The role of personality in predicting exercise behaviour: A systematic review. Health Psychology Update, 13, 14-18.

McGregor, B. A., Bowen, D. J., Ankerst, D. P., Andersen, M. R., Yasui, Y., \& McTiernan, A. (2004). Optimism, perceived risk of breast cancer, and cancer worry among a community-based sample of women. Health Psychology, 23, 339-344. http://dx.doi.org/10.1037/0278-6133.23.4.339

McMillan, B., Higgins, A. R., \& Conner, M. (2005). Using an extended theory of planned behaviour to understand smoking amongst schoolchildren. Addiction Research and Theory, 13, 293-306. http://dx.doi.org/10.1080/16066350500053679

Moan, I. S., \& Rise, J. (2006). Predicting smoking reduction among adolescents using an extended version of the theory of planned behaviour. Psychology and Health, 21, 717-738. http://dx.doi.org/10.1080/14768320600603448

Montano, D. E., Thompson, B., Taylor, V. M., \& Mahloch, J. (1997). Understanding mammography intention and utilization among women in an inner city public hospital clinic. Preventive Medicine, 26, 817-824. http://dx.doi.org/10.1006/pmed.1997.0215

O’Neil, S., Bowling, J. M., Brewer, N. T., Lipkus, I. M., Skinner, C. S., Strigo, T. S., \& Rimmer, B. K. (2008). Intentions to maintain adherence to mammography screening. Journal of Women Health, 17, 1133-1141. http://dx.doi.org/10.1089/jwh.2007.0600

Richard, R., van der Pligt, J., \& de Vries, N. (1996). Anticipated affect and behavioral choice. Basic and Applied Social Psychology, 18, 111-129. http://dx.doi.org/10.1207/s15324834basp1802_1

Robbins, A. S., Spence, J. T., \& Clark, H. (1991). Psychological determinants of health and performance: The tangled web of desirable and undesirable characteristics. Journal of Personality and Social Psychology, 61, 755-765. http://dx.doi.org/10.1037/0022-3514.61.5.755

Rosenstock, I. M., Strecher, V. J., \& Becker, M. H. (1988). Social learning theory and the health belief model. Health Education and Behavior, 15, 175-183. http://dx.doi.org/10.1177/109019818801500203

Rhodes, R. E., Courneya, K. S., \& Jones, L. W. (2002). Personality, the theory of planned behavior, and exercise: A unique role for extroversion's activity facet. Journal of Applied Social Psychology, 32, 1721-1736. http://dx.doi.org/10.1111/j.1559-1816.2002.tb02772.x

Rutter, D. R. (2000). Attendance and reattendance for breast cancer screening: A prospective 3 year test of the theory of planned behavior. British Journal of Health Psychology, 5, 1-13. http://dx.doi.org/10.1348/135910700168720

Schopper, D., \& de Wolf, C. (2009). How effective are breast cancer screening programmes by mammography? Review of the current evidence. European Journal of Cancer, 45, 1916-1923. http://dx.doi.org/10.1016/j.ejca.2009.03.022 
Soskolne, V., Marie, S., \& Manor, O. (2007). Beliefs, recommendations and intentions are important explanatory factors of mammography screening behavior among Muslim Arab women in Israel. Health Educational Research, 22, 665-676. http://dx.doi.org/10.1093/her/cyl132

Steptoe, A., Wardle, J., Vinck, J., Tuomisto, M., Holte, A., \& Wichstrøm, L. (1994). Personality and attitudinal correlates of healthy and unhealthy lifestyles in young adults. Psychology and Health, 9, 331-343. http://dx.doi.org/10.1080/08870449408407492

Taylor, S. D., Bagozzi, R. P., \& Gaither, C. A. (2005). Decision making and the effort in the self-regulation of hypertension: Testing two competing theories. British Journal of Health Psychology, 10, 505-530. http://dx.doi.org/10.1348/135910704X22376

Taylor, S. E., Kemeny, M. E., Aspinwall, L. G., Schneider, S. G., Rodriguez, R., \& Herbert, M. (1992). Optimism, coping, psychological distress, and high-risk sexual behavior among men at risk for Acquired Immunodeficiency Syndrome (AIDS). Journal of Personality and Social Psychology, 63, 460-473. http://dx.doi.org/10.1037/0022-3514.63.3.460

Terán, L., Baezconde-Garbanati, L., Márquez, M., Castellanos, E., \& Belkić, K. (2007). On-time mammography screening with a focus on Latinas with low income: A proposed cultural model. Anticancer Research, 27, $4325-4338$.

Tolma, E., Reininger, B. M., Evans, A., \& Ureda, J. (2006). Examining the theory of planned behavior and the construct of self-efficacy to predict mammography intention. Health Education \& Behavior, 33, 233-251. http://dx.doi.org/10.1177/1090198105277393

Trafimow, D., Sheeran, P., Conner, M., \& Finlay, K. A. (2002). Evidence that perceived behavioral control is a multidimensional construct: Perceived control and perceived difficulty. British Journal of Social Psychology, 41, 101-121. http://dx.doi.org/10.1348/014466602165081

Wasylkiw, L., \& Fekken, G. C. (2002). Personality and self-reported health matching predictors and criteria. Personality and Individual Differences, 33, 607-620. http://dx.doi.org/10.1016/S0191-8869(01)00175-1

\section{Copyrights}

Copyright for this article is retained by the author(s), with first publication rights granted to the journal.

This is an open-access article distributed under the terms and conditions of the Creative Commons Attribution license (http://creativecommons.org/licenses/by/3.0/). 